\title{
Design and Realization of Network Public Sentiment Management Platform for Chinese Universities
}

\author{
Hu Liang ${ }^{1, a^{*}}$, Ding AiChun ${ }^{2,1}$, Zhu YuChi ${ }^{1, c}$ \\ ${ }^{1}$ Department of Humanities and Management, JiangXi Police College, NanChang City, JiangXi \\ Province, P.R.China; \\ a*huliang_thu@163.com, ${ }^{\mathrm{b}}$ acting2312@163.com, ${ }^{\mathrm{C}}$ zhuyuchi_jxga@163.com
}

Keywords: network public sentiment, university, management platform

Abstract. The college network public opinion is the vane of the of China the effectiveness of the college students' collective action, based on hot events of the network public opinion structure characteristics of perception and discrimination will directly determine the development trend of Chinese college students' collective action. Therefore, in order to prevent the adverse effects caused by the information of public opinion on social, public opinion on the network were effective monitoring, to provide decision-making basis for managers, this study by building the network public sentiment management platform(NPS-MIS) to realize guarantee the normal teaching and research in order, promote the development of Chinese college students

\section{Introduction}

College network public opinion refers to the Chinese college students in the network of some of the hot issues demonstrated by a certain size and a clear tendency of the views or opinions of the situation $[1,2]$. In the middle of twenty-first Century, the network technology has become an essential Internet communication skills, today's Chinese college students are among the group of users.

1) College students to participate in the enthusiasm of the network, active thinking. According to the survey, the main problems of college students online attention, the international and domestic major events accounted for $25.4 \%$, social hot and difficult issues accounted for $27.2 \%$, the school's focus problems accounted for $29.1 \%$, other issues accounted for $18.3 \%$. From these data, it is seen that the network of college students are more concerned about the problem of a wide range of ideas.

2) College students' network nationality, democratic consciousness. With the rapid development of China's Internet, it provides a platform for the national consciousness to express more and more. The group of university students have more convenient access conditions and higher level of knowledge and technical ability, they put network as a way of making the country strong and the people rich, expression of national consciousness and patriotic passion of the most important places.

3) College students' ability to identify the network rumors and false information is weak, and the network public opinion tends to be emotional. According to the survey, $6.3 \%$ of the college students often on the Internet to spread, spread false news, $34.4 \%$ of college students have had, but not often on the Internet spread, spread false news, with $59.3 \%$ of college students are not on the Internet to spread, spread false news.

In recent years, the relevant statistics show that China's colleges and universities for network public opinion information processing and not enough time, in response to treatment is lagging behind, have a certain proportion of college students have to public opinion information processing produced not trust psychology. Now nowadays, the university students are using a group of network, network filled with a variety of information, the information on college students' thoughts and behavior produced an inestimable influence. Because of this university will become public opinion events occurred most concentrated in one place. 


\section{System general framework of NPS-MIS}

Chinese University network public opinion management platform is based on the Web platform for information exchange and development of the command and management platform. According to the characteristics and process of network public opinion management, referring to the construction requirements of the relevant safety emergency management platform, combined with the actual operation of the network, the design of the network public opinion management platform in Colleges and universities as shown in Fig. 1.

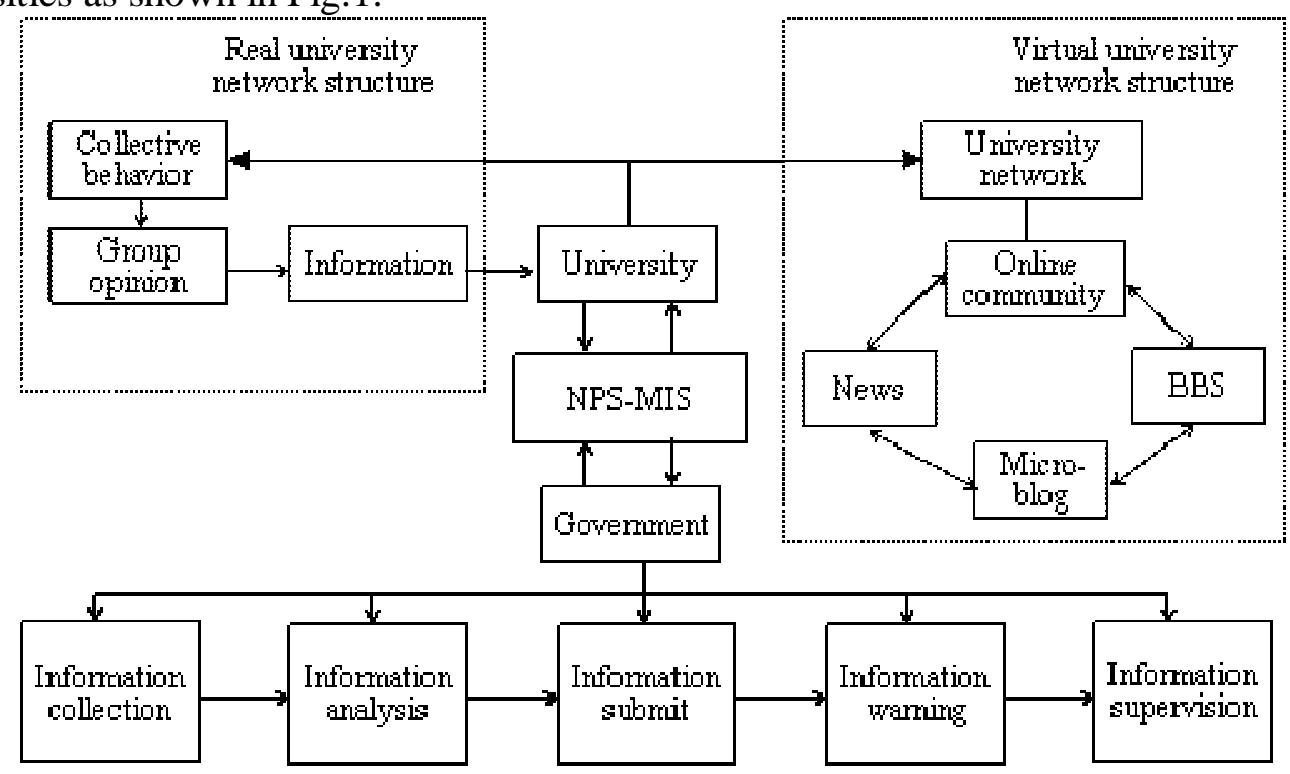

Fig.1 System general framework of NPS-MIS

The network public sentiment management platform designed in this paper includes public sentiment information collection, storage and analysis module. Public sentiment information acquisition module main job is to grab information, provide data support for the upper analysis. Public sentiment information storage module storage the data, using HDFS as a data storage media, then using HBase and Hive as a higher level storage. Public sentiment information analysis through the original web page information processing, including text classification, text clustering, hot spots, as well as the issue of tracking and tracking.

\section{Public sentiment information collection}

Original information collection is the most important task of building public opinion monitoring system. The timing directional information acquisition, unified scheduling by acquisition controller, through the acquisition controller reads corresponding to the site information, including: URL and site templates and other information, then you can use distributed web crawler to collect information, as shown in Fig.2.

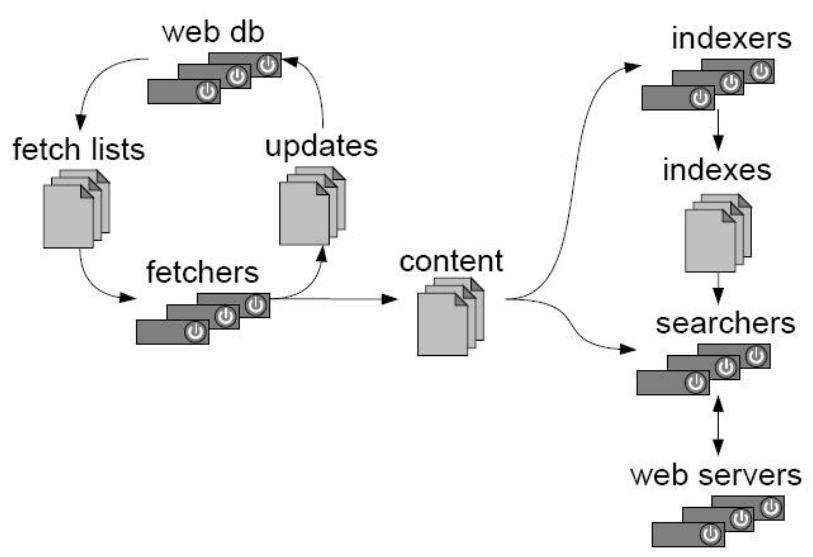

Fig. 2 Public sentiment information collection 


\section{Public sentiment information clustering}

By clustering a group of articles or text information can be similar to the comparison, the more similar articles or text information into the same class. The basic idea is that the initial random given $\mathrm{K}$ cluster centers, according to the nearest neighbor principle, the sample points in each cluster. Then the centroid of each cluster is re calculated by the average method, and the new cluster center is determined.

$$
d_{i}(x)=k_{i}, i=1,2, \ldots, \mathrm{c}, k_{i}=\left[\sum_{i=1}^{n}\left(x_{i}-y_{i}\right)^{2}\right]^{1 / 2}
$$

In this paper, we use the 100000 data as the information source, extract 10000, 15000, 25000 and 50000, the results shown in Fig.3.

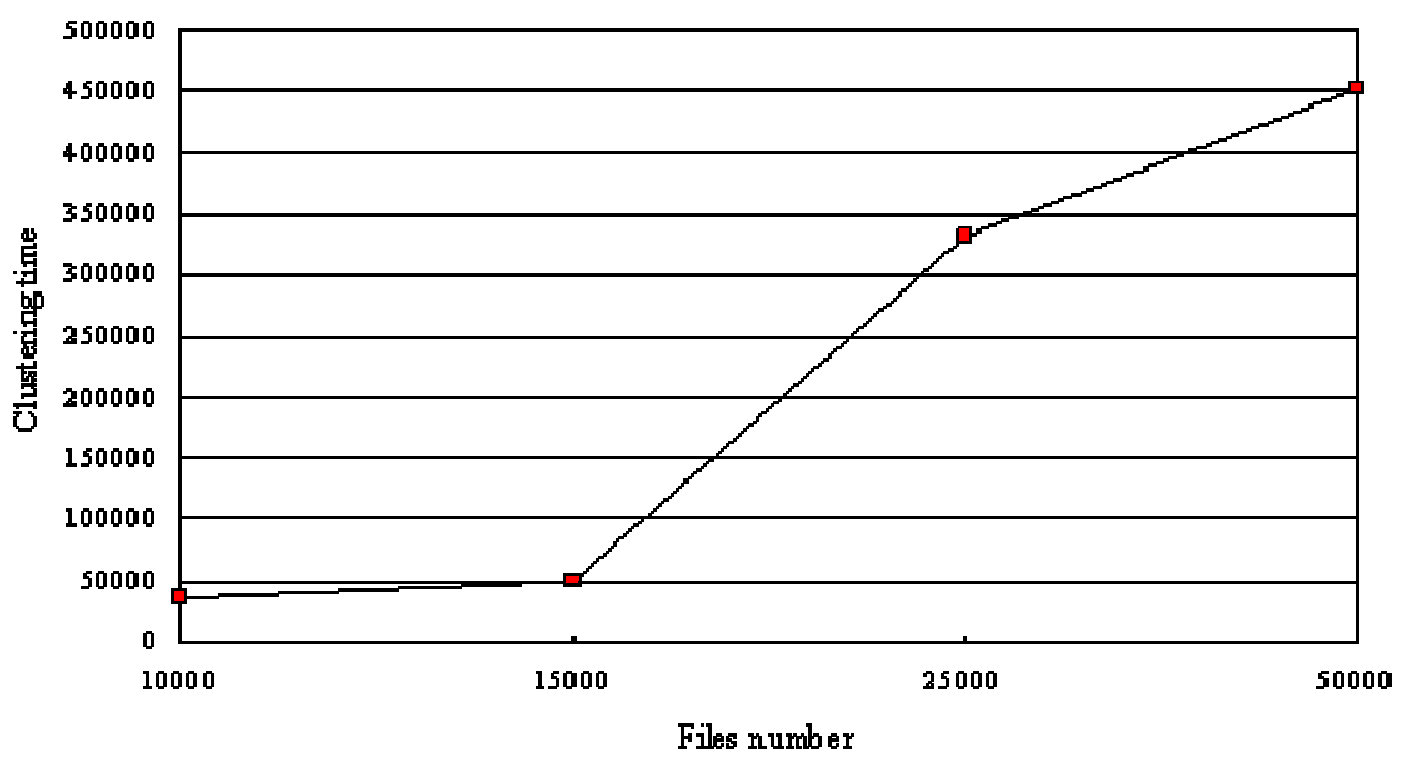

Fig.3 Public sentiment information clustering

\section{Popular topic of public sentiment}

In this paper, the number of information, the source and the speed and other factors are considered, and the following formula is used to compute the popular topics:

$$
F=\frac{r_{n} \times N}{R_{N}}+\frac{r_{d} \times N}{\sum_{i=0}^{N} r_{d}}+\ln \left(t_{n}+100 p_{n}\right)
$$

Among them, $r_{n}$ for this period of time the number of relevant reports, $R_{N}$ for the period of time the total number of reports, $\mathrm{N}$ for this period of time the total number of topics, $\mathrm{r}_{\mathrm{d}}$ for the total number of days, $t_{n}$ for the topic of the number of hits, $p_{n}$ for the topic of the number of comments.

Topic query vector construction process will be training from the words according to its counterpart of $r * \operatorname{idf}(w)$ value from high to low ranking, where $r$ contains the number of reports of word $\mathrm{w}, \operatorname{idf}(\mathrm{w})$ for $\mathrm{w}$ value; take the top $\mathrm{n}$ word composition query vector. The formula is as follows:

$$
d(k)=0.4+0.6 \times t f(w) \times i d f(w)
$$

Through the simulation analysis results of the algorithm, we can see popular topic before scoring five average error rate was 0.3336 and average false alarm rate 0.0325 . Minimum standard cost for 0.4928 , verified the proposed method is feasible and effective system of popular topic, as shown in Table 1. 
Table 1 Experimental results of popular topics

\begin{tabular}{|c|c|l|l|c|c|c|}
\hline Ranking & Score & $\begin{array}{l}\text { Files } \\
\text { number }\end{array}$ & Keyword & $\begin{array}{l}\text { Error } \\
\text { rate }\end{array}$ & $\begin{array}{l}\text { False alarm } \\
\text { rate }\end{array}$ & $\begin{array}{l}\text { Minimum } \\
\text { standard cost }\end{array}$ \\
\hline 1 & 7.20 & 7600 & $\begin{array}{l}\text { The price of vegetables, } \\
\text { tuition, scholarship }\end{array}$ & 34.13 & 3.12 & 49.42 \\
\hline 2 & 6.94 & 7100 & $\begin{array}{l}\text { Grades, exams, remedial } \\
\text { classes }\end{array}$ & 33.25 & 3.56 & 50.69 \\
\hline 3 & 6.51 & 6500 & $\begin{array}{l}\text { Self-study, classroom, } \\
\text { library servant, graduate }\end{array}$ & 35.26 & 3.27 & 51.28 \\
\hline 4 & 5.07 & 5000 & $\begin{array}{l}\text { Civil servant } \\
\text { student, work }\end{array}$ & 3.01 & 46.92 \\
\hline 5 & 4.95 & 4300 & $\begin{array}{l}\text { Papers, scientific research, } \\
\text { project }\end{array}$ & 31.90 & 3.29 & 48.10 \\
\hline
\end{tabular}

\section{Discussion and future work}

This paper attempts through processing, classification and annotation of the college network public opinion data extraction, hot public opinion data contain additional elements of college students attribute the use of templates, construction of network public opinion management platform. This topic research results will deploy for management departments, development is conducive to social stability and development of the decision-making, for management departments to provide multi angle, multi-level query and analysis of college network public opinion data function and warning decision support.

\section{Acknowledgment}

This author's work is supported by JiangXi Research on teaching reform of higher education(JXJG-14-19-1, JXJG-15-19-3), JiangXi Science and technology research project of Education Department(GJJ151193), JiangXi Social Science Planning Projects during the 12th Five-Year Plan(14TQ05) and JiangXi Police College Scientific Research Project(2014QN001).

\section{References}

[1] Wang L. Introduction to public opinion research[M]. Tianjin: Tianjin Academy of Social Sciences Press, 2003: 5-8. (in Chinese)

[2] Liu Y. The application of content analysis method in the analysis of network public opinion information[J]. Journal of Tianjin University, 2006(7): 308-310. (in Chinese)

[3] Zeng R. Internet public opinion information resource sharing research[J]. intelligence Journal, 2009(8): 187-191. (in Chinese)

[4] Yu M, Li Y. Research on the key technology and system architecture of network public opinion[J]. information network security, 2011(1): 21-22, 45. (in Chinese)

[5] Peng Z. On group events and network public opinion[J]. Journal of Shanghai Police College, 2008(1): 46-50. (in Chinese)

[6] Zhang L. The ethical issues in the network public opinion[J]. Theory Circle, 2007(6): 6-7. (in Chinese)

[7] Liu X. Thinking on the research framework of the resonance phenomenon of Internet public opinion[J]. News, 2011(8): 32-33. (in Chinese) 